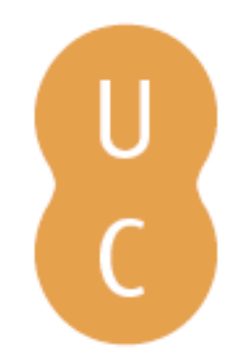

\title{
nommalina
}

\section{A muralha, o templo e o aqueduto na tradição de Sertório construtor da Évora romana (Sécs. XVI-XIX)}
Autor(es):
Rodrigues, Paulo Simões
$\begin{array}{ll}\text { Publicado por: } & \text { Associação Portuguesa de Estudos Clássicos; Centro de Estudos } \\ \text { Clássicos e Humanísticos; Imprensa da Universidade de Coimbra }\end{array}$
URL
URI:http://hdl.handle.net/10316.2/31567
DOI:
DOI:http://dx.doi.org/10.14195/978-989-8281-69-2_22
Accessed : $\quad$ 26-Apr-2023 07:41:30

A navegação consulta e descarregamento dos títulos inseridos nas Bibliotecas Digitais UC Digitalis, UC Pombalina e UC Impactum, pressupõem a aceitação plena e sem reservas dos Termos e Condições de Uso destas Bibliotecas Digitais, disponíveis em https://digitalis.uc.pt/pt-pt/termos.

Conforme exposto nos referidos Termos e Condições de Uso, o descarregamento de títulos de acesso restrito requer uma licença válida de autorização devendo o utilizador aceder ao(s) documento(s) a partir de um endereço de IP da instituição detentora da supramencionada licença.

Ao utilizador é apenas permitido o descarregamento para uso pessoal, pelo que o emprego do(s) título(s) descarregado(s) para outro fim, designadamente comercial, carece de autorização do respetivo autor ou editor da obra.

Na medida em que todas as obras da UC Digitalis se encontram protegidas pelo Código do Direito de Autor e Direitos Conexos e demais legislação aplicável, toda a cópia, parcial ou total, deste documento, nos casos em que é legalmente admitida, deverá conter ou fazer-se acompanhar por este aviso.

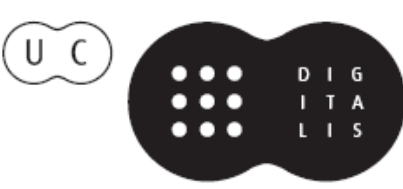




\section{Espaços e Paisagens}

Antiguidade Clássica

e Heranças Contemporâneas

Vol. III

Francisco Oliveira, Jorge Oliveira e Manuel Patrício

IMPRENSA DA UNIVERSIDADE DE COIMBRA 


\title{
A MURALHA, O TEMPLO E O AQUEDUTO NA TRADIČ̃̃O DE SERTÓRIO CONSTRUTOR DA ÉVORA ROMANA (SÉCS. XVI-XIX).
}

\author{
PaUlo Simões Rodrigues \\ Universidade de Évora \\ Departamento de História e Centro de História da Arte \\ e Investigação Artística
}

\begin{abstract}
By writing the History of Antiquity of the City of Évora (1553), André de Resende gave rise to a historiographic tradition that considered the presence of Sertório in Évora, city where he supposedly lived, a certainty, as well as his responsibility in the edification of the first belt of walls of the city, and in the edification of the temple and supposed aqueduct. Although it is based on fragile and very empirical associations of Roman architectonic traces present in the city with the archeology and readings of Plutarch, who mentions the presence of the Roman general in Hispania, such a tradition was cyclically revisited and revitalized until the nineteenth century, by authors like Diogo Mendes de Vasconcelos, Manuel Fialho, António Franco, Francisco da Fonseca, and Augusto Filipes Simões. The longevity of the tradition is explained by the manner in which the material evidence that supposedly confirm it was used to ascertain the antiquity of Évora and the relevance of its past, which was more ancient than the Kingdom itself and whose relevance was confused with that of the Roman Empire. We propose to address such a tradition because it demonstrates the perennial nature of history and classical culture as a paradigm of civilization, and also demonstrates how this paradigm was able to shape the way in which all the successive ages interpreted Roman architecture.
\end{abstract}

Keywords: architecture, Évora, historiography, monuments, Sertorius

Palavras-chave: arquitectura, Évora, historiografia, monumentos, Sertório

No ano de 1864, o número 6 do jornal Archivo Pittoresco abria com uma gravura do aqueduto de Évora, designadamente do troço que entra na área intramuros, sobre o pano da muralha, entre a Porta da Lagoa e a Porta de Avis, no flanco nordeste da cidade. Destaca-se a imagem pela representação, no limite do eixo que o aqueduto traça, acima da cota do muro da cerca, da torre circular de uma Mãe de Água, decorada com elementos clássicos, em tudo igual a outra que existia frente à fachada da Igreja de S. Francisco, desmantelada em 1872. Segundo o texto que acompanhava a gravura, da autoria do escritor Inácio Vilhena Barbosa (1811-1890), um dos fundadores e principais redactores do Archivo Pittoresco, a Mãe de Água que aparecia na ilustração, juntamente com a do largo de S. Francisco, eram estruturas remanescentes do primitivo aqueduto romano, mandado construir pelo general Quinto Sertório no século I a.C. e reconstruído por D. João III no século XVI. O desenho clássico das duas torres - com as suas colunas dóricas, os nichos, a abóbada e a lanterna - e o 
uso de tijolo para as edificar corroboravam essa asserção e fundamentavam a denominação que o artigo lhe atribuía: "Aqueducto de Sertorio"1.

Nem a imagem, nem a teoria que a imagem ilustrava constituíam novidade em 1864. A imagem repetia uma já publicada no L'Univers Pittoresque, cuja primeira versão portuguesa saiu impressa no Archivo Popular. O seu provável modelo terá sido uma gravura editada pelo Magasin Pittoresque (tome III, $\mathrm{n}^{\circ}$. 49, Décembre, p. 385) em 1835, em que o ângulo da visão do espectador está mais aproximado da figuração da Mãe de Água. Quanto à teoria da fundação romana do aqueduto, comprovada pela sobrevivência das duas torres, havia sido já veiculada por Vilhena Barbosa no mesmo periódico, no ano anterior ${ }^{2}$.

Embora a imagem e o artigo que o Archivo Pittoresco havia dedicado ao aqueduto de Évora tivessem, efectivamente, a finalidade da divulgação de um conhecimento estabelecido e não de uma descoberta arqueológica ou de uma conclusão historiográfica recentes, padeciam de uma incongruência que o historiador Augusto Filipe Simões (1835-1884), então a dirigir a Biblioteca Pública de Évora, se apressou a denunciar nas páginas do jornal eborense Folha do Sul. Num artigo que intitulou sintomaticamente de "O aqueducto de Evora e o Archivo Pittoresco", declarava aquilo que todos os eborenses sabiam: a Mãe de Água representada na ilustração do Archivo Pittoresco e um dos sustentáculos da tese da origem romana do aqueduto, partilhada por Vilhena Barbosa, não existia ${ }^{3}$. Apenas a torre sita no largo de S. Francisco era real.

Vilhena Barbosa reage ao artigo de Augusto Filipe Simões dirigindo-lhe uma carta justificativa, na qual explica que a intenção da gravura do Archivo Pittoresco era reconstituir graficamente uma estrutura que não existia de facto, mas que, segundo o humanista e arqueólogo eborense André de Resende (c. 1500-1573), teria existido igual "na fórma e na architectura" ao de S. Francisco ${ }^{4}$. André de Resende referir-se-ia aos dois pavilhões como romanos numa sua Apologia pelo aqueducto de Sertorio contra D. Miguel da Silva, bispo de Vizeu, texto desaparecido, mas que Vilhena Barbosa afirmava ter consultado através de uma cópia do século XVII ou XVIII ${ }^{5}$.

Percebe-se por que razão Vilhena Barbosa recorreu a André de Resende como argumento de autoridade para defesa do seu artigo. Enquanto autor de História da Antiguidade da Cidade de Évora, obra de cariz historiográfico publicada em 1553, ele fora o primeiro a associar aquela urbe alentejana a Quinto Sertório, o general romano que, em conformidade com as fontes

${ }^{1}$ I. V. Barbosa 1864.

${ }^{2}$ I. V. Barbosa 1863.

${ }^{3}$ I. V. Barbosa 1867a.

${ }^{4}$ A missiva de I. V. Barbosa foi posteriormente publicada pelo próprio no jornal Archivo Pittoresco, no n. ${ }^{\circ} 5$ de 1867 , p.34-35.

5 Juntamente com a Apologia, Vilhena Barbosa também terá consultado cópias da correspondência trocada entre o humanista eborense e o Bispo de Viseu. Todos estes documentos, Apologia e correspondência, seriam duplicados, redigidos com letra de finais do século XVII ou dos inícios do século XVIII, de outras cópias guardadas na livraria do Conde do Vimieiro. I. V. Barbosa 1867b. 
literárias latinas ${ }^{6}$, teria vivido na Hispânia durante as guerras civis do século I a.C. No texto de Resende, Évora era apresentada como a principal residência na Península Ibérica do general romano, a quem atribuía a responsabilidade pela construção da sua primeira cintura de muralhas e do primitivo aqueduto da Água da Prata: "Item mandou Sertório cercar a cidade de cantaria lavrada, como se inda em muitas partes mostra por onde é a cerca velha, e assi fez trazer a água da Prata ao pórtico [muito provavelmente o templo] em o mais alto da cidade"

$\mathrm{Na}$ sequência imediata da afirmação citada, André de Resende alude efectivamente a uma "apologia ou resposta que contra o bispo de Viseu" escrevera, por motivo de este prelado, escrivão da puridade de D. João III, ter declarado ao rei que os romanos nunca haviam edificado um aqueduto em Évora, nem sequer Sertório tinha alguma vez morado na cidade transtagana ${ }^{8}$. Diogo Mendes de Vasconcelos (1523-1599), amigo e biógrafo de André de Resende, no seu Libro V do Municipio Eborense, publicado em latim no ano de $1593^{9}$, corrobora a redacção da dita Apologia ... ao mencionar a sua intenção de a mandar imprimir, juntamente com outras pequenas obras do mesmo autor, para que não se perdessem ${ }^{10}$. À Apologia ... ter-se-iam seguido dois opúsculos mais desenvolvidos sobre aquedutos, redigidos por Resende a mando do rei, a quem os entregou no início de 1543 e dos quais também se perdeu o rasto ${ }^{11}$.

Apesar de hoje não podermos conhecer os conteúdos quer da Apologia, quer dos dois opúsculos dedicados aos aquedutos, as circunstâncias da sua produção, a edificação do Aqueduto da Água da Prata em Évora e a controvérsia gerada com D. Miguel da Silva, permitem-nos compreender melhor o esforço investido por André de Resende na demonstração cabal da presença de Sertório em Évora, alicerçando-a num testemunho empírico muito concreto, uma inscrição epigráfica que transcreve no capítulo III da História

${ }^{6}$ Plutarco (Sertório), Apiano (História Romana), Lúcio Floro (Epitome da História de Tito Livio), Paulo Orósio (História Contra os Pagãos), Valério Máximo (Factos e Ditos Memoráveis), Frontino (Strategemata), etc. A. Resende 1996 159-160.

${ }^{7}$ A. Resende 1963 17-18.

${ }^{8}$ A. Resende 196318.

${ }^{9}$ Publicado por necessidade de completar De Antiquitatibus Lusitaniae (As Antiguidades da Lusitânia) de Resende, cujo Livro Quatro, o último, que trata das cidades, não inclui Évora.

10 “Ao qual [D. Miguel da Silva, bispo de Viseu] tam compridamente respondeo Rezende com h ua muy fermoza Apologia, que nella paresse emborcou e esgotou em favor da Patria os escondidos thezouros, e arrecadados cabedais de suas antiguidades e sabedoria. [...] Esta Apologia temos nõs tençam de mandar imprimir juntamente com outras obrinhas delle, que separadamente foram impressas, e ja estam esquecidas e quazi consumidas e acabadas". D. M. Vasconcelos, "Libro V do Municipio Eborense", in B. J. S. Farinha 178545.

11 "Também falei disso em dous livros dos aquedutos que a El-Rei, Nosso Senhor, per seu mandado escrevi e, portanto, agora nom é necessário torná-lo repetir. Antes me parecia que os mesmos livros, porquanto tratam como se devem fazer os aquedutos e como conservar, se deviam ajuntar a este tratado e às vezes se lerem para que deles se tomasse algua utilidade, se a neles há". A. Resende 1963 18. "Há alguns anos, tendo-me eu dirigido a Almeirim, para ver o rei e lhe oferecer dois opúsculos que a seu pedido eu compusera sobre aquedutos". A. C. Ramalho 1982 48-352. Ver ainda S. Deswarte 1992b 171. 
da Antiguidade da Cidade de Évora ${ }^{12}$, provavelmente descoberta durante os seus périplos arqueológicos pela cidade e seus arredores.

O registo epigráfico vinha não só comprovar, em termos materiais, as fontes literárias da Antiguidade como também, associado ao monumento edificado (a muralha e o aqueduto), atribuir, inovadoramente, um relevante valor heurístico à arquitectura. Esta, por outro lado, serviu a André de Resende de reforço ao testemunho prestado pelas inscrições, cuja idoneidade havia sido posta em causa pelo Bispo de Viseu, não sem razão, como ficou demonstrado por um estudo de José de Encarnação ${ }^{13}$.

D. Miguel da Silva havia acusado André de Resende de forjar um "letreiro" que comemorava o empreendedorismo de Sertório na construção da muralha e de um aqueduto de Évora: "Quinto Sertorio em louvor do seu nom e da campanha dos muy esforçados Eborenses, per seu ardimento na guerra Celtiberia, cercou e afortalezou a Cidade Municipíio de soldados velhos, e aposentados, e fez trazer por níveis muita agoa colhida de varias fontes para proveito publico do dito Municipio"14. Sustentava-se a acusação no facto do general aparecer com o nome da mãe e não com o do pai, como era costume entre os romanos. Segundo o bispo de Viseu, de acordo com o veiculado por Diogo Mendes de Vasconcelos, André de Resende fora impelido a falsificar a inscrição pelo seu desejo de persuadir D. João III a construir um aqueduto em Évora, convencendo-o que, na prática, estava a reconstruir uma preexistência ${ }^{15}$. Ora, tendo em conta que a contenda com D. Miguel da Silva terá decorrido nos anos de 1530, em virtude da inauguração do Aqueduto da Água da Prata ter acontecido em 1537 e do bispo ter fugido de Portugal em 1540, deduzimos que o "letreiro" em causa foi intencionalmente não incluindo entre os documentos epigráficos transcritos por André de Resende na História da Antiguidade da Cidade de Évora, impresso em 1553. A sua não inclusão poderá significar que, apesar da ausência de D. Miguel da Silva do país, este permanecia um assunto sensível para Resende. De resto, devemos a Diogo Mendes de Vasconcelos o conhecimento desta placa comemorativa, integrada por ele no Livro V do Municipio Eborense, quando historia, em defesa do seu amigo Resende, a controvérsia despoletada pelo bispo de Viseu ${ }^{16}$.

A importância concedida a Sertório por André de Resende na História da Antiguidade da Cidade de Évora ultrapassava, no entanto, o circunstancialismo da construção do aqueduto de Évora. Visava sobretudo mostrar a ancestralidade da cidade alentejana e a antiguidade do seu prestígio, que remontavam à romanização e que estavam expressas, acreditava Resende, na elevação de Évora ao estatuto de município, concedido por Júlio César, de que decorreu o cognome então recebido de Liberalitas Iulia, a autorização para cunhar

\footnotetext{
12 A. Resende 196317.

13 J. Encarnação 1991 193-221.

14 Transcrição publicada em S. Deswarte 1989 86, 87, 210.

${ }^{15}$ S. Deswarte 198987.

16 Idem, 86.
} 
moeda e a capacidade para ter clero próprio ${ }^{17}$. André de Resende parece querer aplicar o louvor do rei arquitecto da felicidade e do bem comum - patente nas crónicas, nas entradas reais, nos panegíricos, nas orações universitárias, nos tratados de educação de príncipes - a Sertório ${ }^{18}$. Ao considerar que D. João III tinha reconstruído o aqueduto romano, estava a fazer reflectir o louvor do seu primeiro construtor, Sertório, no rei de que era súbdito. Parece que D. Miguel da Silva não estava enganado quanto às verdadeiras motivações de André de Resende.

A suposta preexistência de um aqueduto romano também se inscrevia no contexto mais amplo da condição histórica da cidade, factor que foi fundamental para o sucesso da tese "sertoriana" de Resende nos anos sequentes, triunfante sobre a suspeição que lhe fora levantada - assim é atestado pela ordem dada por D. Filipe II em 1602, aquando da promulgação do novo regimento do Aqueduto da Água da Prata, de expor publicamente, na Praça Maior (actual Praça do Geraldo), todas as inscrições antigas alusivas à presença de Sertório em Évora ${ }^{19}$. Esta consagração da tese "sertoriana" ficou a dever-se tanto à natureza conjuntural do discurso de André de Resende, que se enquadrava nas descrições panegíricas das cidades tão caras à cultura moderna ${ }^{20}$, como à sua actualização pelos autores que se seguiram na narrativa da história de Évora.

O primeiro a enriquecer a tese "sertoriana" é Frei Bernardo de Brito (15691617), na sua Monarchia Lusitana, publicada em duas partes nos anos de 1597 e 1609. Nesta história do reino, que recua aos seus antecedentes, Frei Bernardo de Brito faz alusão ao achado acidental de uma inscrição antiga aquando da construção da Igreja de S. Luís, a qual continha o presumível epitáfio de Quinto Sertório, em que este era intitulado de "Capitão dos Lusytanos" e se rogava à deusa Diana que encaminhasse o seu corpo até aos Campos Elísios ${ }^{21}$. A discutível romanidade do registo epigráfico torna-se logo evidente na relação estabelecida entre a Lusitânia, Sertório e a divindade Diana, que está em harmonia com a biografia que Plutarco faz do "Capitão dos Lusytanos" nas Vidas Paralelas.

Plutarco conta como Sertório montou um ardil para elevar a moral dos seus soldados na Hispânia, utilizando uma corça que lhe havia sido oferecida por um camponês local para fingir que fora uma dádiva da deusa Diana, com a missão de avisá-lo, durante o sono, dos perigos que o ameaçavam e das medidas que devia tomar para se defender ${ }^{22}$. O episódio é invocado por

${ }^{17}$ A. Resende 1963 23, 27-31.

18 N. N. C. Soares 2003601.

${ }_{19}$ T. Espanca 1944 33-35.

${ }^{20}$ N. N. C. Soares 2003598 e 599. De salvaguardar, contudo, que o discurso de André de Resende sobre Évora não obedece exactamente ao modelo do elogio da urbe quinhentista, que, por sua vez, seguia as coordenadas da cidade ideal do Renascimento. Resende não faz quaisquer referências à organização sócio-económica ou à estética arquitectónica de Évora, é o passado da cidade que idealiza ao pô-la a protagonizar factos importantes das histórias de Roma, da cristianização e do reino.

${ }^{21}$ B. Brito $2004303 v^{\circ}-304$.

${ }^{22}$ Plut. Sert. 10-11. 
Camões em Os Lusíadas (1572): "Vês, connosco também vence as bandeiras / Dessas aves de Júpiter validas; / Que já naquele tempo as mais guerreiras / Gentes de nós souberam ser vencidas. / Olha tão sotis artes e maneiras / Pera adquerir os povos, tão fingidas: / A fatídica cerva que o avisa. / Ele é Sertório, e ela a sua divisa"23. Retoma-o Manuel Fialho (1646-1718) no manuscrito Évora Ilustrada (c. 1718), ao declarar que o templo romano da cidade fora dedicado à deusa da caça, cabendo-lhe a paternidade da tradicional e popular designação de "Templo de Diana"24. A intenção foi, mais uma vez, estabelecer um vínculo directo entre um vestígio material / arquitectónico do passado e a figura histórica de Quinto Sertório, a fim de o monumento poder testemunhar a ligação do general romano à cidade.

Na Monarchia Lusitana, Frei Bernardo de Brito também menciona duas sumptuosas casas que Sertório teria na cidade para sua residência, sem especificar onde. Frei António Brandão (1584-1637), na terceira parte da Monarchia Lusitana (1630), localiza-as nas casas que os Sortelha cederam para a instalação do Convento do Salvador e que estavam coladas ao seu palácio, edifício onde a Câmara Municipal está actualmente sedeada ${ }^{25}$. Gaspar Estaço (1560-1626), em 1625, indica, com precisão, o Convento do Salvador como tendo sido levantado sobre os vestígios arquitectónicos do Palácio de Sertório ${ }^{26}$.

No século XVIII, a presença de Sertório em Évora e a sua responsabilidade na edificação da primeira cintura amuralhada da cidade, do aqueduto e do templo era um dado adquirido. Confirmamo-lo nos viajantes estrangeiros que escreveram sobre Évora. É o presumível carácter clássico do aqueduto que atrai a atenção do arquitecto inglês James Murphy (1760-1814), que o desenha com acentuado pormenor, em particular a cobertura da Mãe de Água de S. Francisco, mais o templo, com os vãos intercolunares entaipados para que servisse de açougue, função que mantinha desde a Idade Média ${ }^{27}$. Na centúria seguinte, houve quem chegasse a considerar que o aqueduto era um dos mais belos exemplares da arquitectura clássica que ainda se conservavam em Portugal $^{28}$. Mas foi também no século XIX que se manifestaram as primeiras dissidências da tese "sertoriana" anteriores a Augusto Filipe Simões. Em 1844, o bispo de Beja, Manuel Pires de Azevedo Loureiro, numa carta enviada à Revista Universal Lisbonense e divulgada naquele periódico a 25 de Abril desse ano, opinava contra o "erro popular" que dedicava o templo de Évora à deusa Diana, com o argumento que os romanos antigos destinavam a ordem coríntia aos deuses e a jónica às deusas. Sendo o templo de Évora da ordem

${ }^{23}$ L. V. Camões, Os Lusiadas, 8, 8.

${ }^{24}$ M. Fialho 194525.

${ }^{25}$ A. Brandão 1973285.

${ }^{26}$ G. Estaço, "Várias Antiguidades de Portugal” in B. J. S. Farinha 1785 123-125.

${ }^{27}$ A primeira visita de James Murphy a Évora decorreu entre 1789 e 1790 . A narrativa e os desenhos da sua viagem foram publicados em 1795, no volume Travels in Portugal. J. Murphy $1998255,257,259-264$.

${ }^{28}$ Ver A. Balbi 2004 196; e J. Urcullu 1837 85-86. 
coríntia, fora necessariamente consagrado a um deus ${ }^{29}$. Dois anos depois, o Conde Athanasius Rackzynski, ministro do rei da Prússia em Portugal de Maio de 1842 a 1845, declarou com ironia que do antigo aqueduto romano só restavam vestígios e, mesmo assim, havia que descobri-los ${ }^{30}$.

O desenvolvimento dos estudos arqueológicos no século XIX e a aplicação dos princípios do pensamento positivista às diferentes áreas do saber a partir dos anos de 1860, que na História e na Arqueologia conduziu à regulação da dedução especulativa pelos limites impostos pelos conteúdos e pela natureza dos documentos, veio fomentar a reavaliação crítica da contribuição de Sertório para a Évora romana. Porém, é precisamente esse espírito positivista que obriga Augusto Filipe Simões a recuar e a aceitar a convicção dominante de que o aqueduto de Évora não era uma construção quinhentista de raiz, mas um restauro, entendido no seu significado mais extremo de reconstrução, da preexistência romana ${ }^{31}$. Ou seja, o bibliotecário eborense vê-se obrigado a render-se à evidência da cópia da Apologia... descoberta por Vilhena Barbosa, conforme foi atrás enunciado, cuja superior relevância é sublinhada por ele, pois, até àquele momento, era conhecida somente por citação.

Augusto Filipe Simões faz publicar a missiva de Vilhena Barbosa no jornal eborense Folha do Sul, acrescentando-lhe uma série de observações relativas à sua inflexão que provocam alguma controvérsia local, o que denota não ser este tema pacífico em Évora, tal como no século $\mathrm{XVI}^{32}$. Também não o era ainda para Augusto Filipe Simões, que retoma a questão após cerca de dois anos de observação, estudo e reflexão. Em nova missiva dirigida a Vilhena Barbosa, datada de 12 de Julho de 1866, ele reconsidera a sua posição anterior, concluindo que a torrinha de S. Francisco não era romana e que a da entrada da cidade não tinha sequer existido. Sobre esta última, não havia qualquer registo ou memória na literatura, nem restavam vestígios materiais, incluindo dos arcos que deveriam suportar uma construção com as suas supostas dimensões, para além da área disponível ser insuficiente para a base circular de uma Mãe de Água igual à do largo de S. Francisco. Relativamente a esta, a análise comparativa com o que restava da galeria principal do paço de D. Manuel, a chamada Galeria das Damas ou Trem, permitiu-lhe verificar que tinham sido construídas com tijolos e pedras iguais, devendo ser, por isso, coetâneas ${ }^{33}$.

A prova material impôs-se ao documento escrito, cuja credibilidade era fragilizada por não ser um original, e Vilhena Barbosa reconsidera a sua posição, aceitando a conclusão de Augusto Filipe Simões. Vilhena Barbosa admite que as cópias da Apologia ... e da correspondência que consultou podiam ser apócrifos ${ }^{34}$. Também a imagem do Univers Pittoresque, que servira

${ }^{29}$ M. P. A. Loureiro 1844430.

${ }^{30}$ A. Raczynski 1846359.

${ }^{31}$ I. V. Barbosa 1867 34-35.

${ }^{32}$ A. F. Simões 186464 1-2.

${ }^{33}$ I. V. Barbosa 186747.

${ }^{34} \mathrm{Em}$ virtude de terem pertencido à livraria do Conde do Vimeiro, conhecido por pagar generosamente pela aquisição tanto de manuscritos raros como, na falta dos originais, de 
de modelo às do Archivo Popular e ao Archivo Pittoresco, devem ter resultado da má interpretação que Adrien Balbi, a sua fonte, fez de James Murphy, que descreve a Mãe de Água do largo de S. Francisco na entrada da cidade, provavelmente por estar localizada no limite da muralha, nas proximidades da Porta do Rossio.

Não se pense, contudo, que se encerrou aqui a tradição erudita de Sertório construtor da Évora romana. Ainda é convocada no dicionário corográfico Portugal Antigo e Moderno, no contributo "Évora", de Pinho Leal ${ }^{35}$, e Gabriel Pereira é obrigado a criticar os seus fundamentos históricos e arqueológicos com veemência entre 1879 e 1884, garantindo que mesmo sem Sertório, o passado de Évora permanecia na esfera do paradigma de civilização que era o Império Romano ${ }^{36}$, que se mantinha garante da antiguidade e do valor histórico da cidade alentejana.

\section{Bibliografia}

Archivo Pittoresco, Lisboa, 1863 (n. $\left.{ }^{\circ} 36\right), 1864 *\left(\mathrm{n} .{ }^{\circ} 6\right), 1867$ (n. ${ }^{\circ} 5$ e n. $\left.{ }^{\circ} 6\right)$.

A. Balbi (2004), Essai statistique sur le royaume de Portugal et d'Algarve. Tome Second. Lisboa, IN - CM, 2 vols.

I. V. Barbosa (1863), "O Arco Triumphal Romano da Praça de Evora", Archivo Pittoresco 36286.

I. V. Barbosa (1864), s/título, Archivo Pittoresco 6 41-42.

I. V. Barbosa (1867a) "Aqueducto de Evora I", Archivo Pittoresco 5 34-35.

I. V. Barbosa (1867b) "Aqueducto de Evora", Archivo Pittoresco 648.

Frei António Brandão (1973), Monarquia Lusitana II. Lisboa, IN - CM.

Frei Bernardo de Brito (2004), Monarquia Lusitana I. Introd. de A. da Silva Rego. 15 , s.l., IN - CM.

Luís Vaz de Camões (s.d.), Os Lusíadas. Porto, Porto Editora.

Sylvie Deswarte (1989), Il "Perfeito Cortegiano". D. Miguel da Silva. Roma, Bulzoni Editore.

Sylvie Deswarte (1992a), Ideias e Imagens em Portugal na Época dos Descobrimentos. Francisco de Holanda e a Teoria da Arte. Lisboa, Difel.

Sylvie Deswarte (1992b), "Aqueducto de Évora I", Archivo Pittoresco, 534.

José Encarnação (1991), "Da Invenção de Inscrições Romanas pelo Humanista André de Resende", Biblos 67 193-221.

Túlio Espanca (1944), "O Aqueduto da Água da Prata", Cadernos de Estudo e Arte Eborense. Évora, Nazareth \& Filho, Lda.

Bento José de Sousa Farinha (1785), Colleçam das Antiguidades de Évora Escriptas por Andre de Resende, Diogo Mendes de Vasconcellos, Gaspar Estaco, Fr. Bernardo de Brito e Manoel Severim de Faria. Lisboa, Officina de Filipe da

falsificações. I. V. Barbosa 186748.

${ }^{35}$ A. S. A. B. P. Leal 1874 89-91.

${ }^{36}$ G. Pereira 194739. 
Silva e Azevedo.

Manuel Fialho, António Franco (1945), Évora Ilustrada. Introd. Armando de Gusmão. Évora, Edições Nazareth,

Augusto Soares d'Azevedo Barbosa de Pinho Leal (1874), Portugal Antigo e Moderno. 3. Lisboa, Livraria Editora de Mattos Moreira \& Cia.

M. A. Azevedo Loureiro (1844), "Sobre o Templo Romano de Évora”, Revista Universal Lisbonence 36.

James Murphy (1998), Viagens em Portugal. Lisboa, Livros Horizonte.

Gabriel Pereira (1947), "Évora Romana. 1ª Parte. O Templo Romano. As inscrições Lapidares". in Estudos Eborenses. vol. 1. Évora, Edições Nazareth, 33-55.

Conte Athanasius Raczynski (1846), Les Arts en Portugal. Léttres adrésses a la Societé Artistique et Scientifique de Berlin et accompagnés de documents. Paris.

Américo da Costa Ramalho (1983), “A Conversão Maravilhosa do Português D. Gil um diálogo latino quase ignorado - da autoria de André de Resende”, Estudos sobre o século XVI. Lisboa, IN-CM, 348-352.

André Resende (1996), As Antiguidades da Lusitânia. Lisboa, Fundação Calouste Gulbenkian.

André Resende (1963), "História da Antiguidade da Cidade de Évora", Obras Portuguesas. Lisboa, Livraria Sá da Costa, 3-69.

A. F. Simões (1864), "Descobrimento Archeologico", Folha do Sul 62.

Nair de Nazaré Castro Soares (2003), Cidades ideais e elogio de cidades no Renascimento e em Damião de Góis. In Congresso Internacional Damião de Góis na Europa do Renascimento. Braga, Universidade Católica Portuguesa, 583-608.

J. Urcullu (1837), Tratado elementar de Geografia, Astronomia, Fizica, Historica ou Politica Antiga e Moderna. 2. Porto, Tipografia Comercial Eborense. 